\title{
The Acoustic Emission Response of Intact Quartzite Under Uniaxial Compression
}

\author{
W.J. Darlington Department of Civil Engineering, Monash University, Australia \\ P.G. Ranjith Department of Civil Engineering, Monash University, Australia \\ S.K. Choi CSIRO Petroleum, Australia
}

J. Kodikara Department of Civil Engineering, Monash University, Australia

\begin{abstract}
This paper presents the results of uniaxial compression tests conducted on quartzite samples. The tested quartzite samples consisted of $83 \mathrm{~mm}$ diameter cores that were cut to a length roughly twice their diameter. The specimens were cored from a depth of between 68-78 $\mathrm{m}$. The stress-strain and acoustic emission (AE) responses were monitored throughout the tests. The results obtained for the intact specimens are believed to be typical, and are in general agreement with the results of other researchers. The tests produced a recognisable AE peak prior to the peak axial strength of the specimen being reached. The axial stress at which this AE peak occurs corresponds to a value of around $90 \%$ of the specimen's UCS (unconfined compressive strength). This is due to the formation of new fractures and shear mobilisation of established failure planes prior to failure that emits large amounts of AE energy.
\end{abstract}

\section{Introduction}

AE technology is a relatively recent addition to the rock mechanics laboratory and field of study. Much work has been done to assess the AE-strength relationship of hard rock (Chang and Lee, 2004; Eberhardt et al., 1997; Eberhardt et al., 1998; Eberhardt et al., 1999; Filimonov et al., 2005). AE monitoring has previously been used to assess the failure processes exhibited by intact rock, this has included monitoring the points at which coalescence of microfractures has initiated and ultimately led to the complete failure of the entire specimen. Here the pioneering work of Lockner et al. (1991) and Lockner (1993) should be examined.

Lockner et al. (1991) presented results of a single triaxial test (with a constant confining pressure of $50 \mathrm{MPa}$ ) on a Westerly granite cylinder of $76.2 \mathrm{~mm}$ in diameter. Six piezoelectric sensors monitored the highfrequency AE events, while an additional four sensors monitored the P-wave (compressional) velocities. By recording relative arrival times and amplitudes of $\mathrm{AE}$ events, three dimensional locations of $\mathrm{AE}$ hypocentres resulted in imaging of fracture nucleation and propagation. $\mathrm{AE}$ event origins were reported to an estimated $\pm 3 \mathrm{~mm}$ accuracy. A specially designed loading device maintained a constant AE rate enabling study of the post peak regions of failure (an area not captured well using traditional loading systems). These post-peak results indicated that a macro fault formed while under quasi-static conditions.

It is clear that $\mathrm{AE}$ monitoring of intact rocks can lead to a better understanding of the interaction between the coalescing micro fractures and visible, macro fractures in the failure process of the rock fabric. Much of the earlier work in relation to the AE response of rock was centred on establishing the rock stress history (i.e. the Kaiser effect). To this end, Yoshikawa and Mogi (1981) conducted uniaxial compression tests on cylindrical samples of 20 and $30 \mathrm{~mm}$ in diameter with a length three times the diameter.

Research done by Eberhardt et al. (1997) explored the progressive crack damage of granitic specimens using a combination of $\mathrm{AE}$ and strain gauge data. They suggest that $\mathrm{AE}$ data may be used as a more reliable measure of crack damage in rock when compared to the traditional methods that assess changes in gradient of the axial stress versus volumetric strain curve. The latter form of analysis being highly subjective and in some cases some of the stages in the failure process are not easily defined. Brace (1964) and Bieniawski (1967) have classified the stages in brittle failure as: 
- Crack closure.

- Linear elastic deformation.

- Crack initiation and stable crack growth.

- Critical energy release (onset of dilatancy) and unstable crack growth.

- Failure and post peak behaviour.

The earlier work of Cox and Meredith (1993) should be noted here. Through quantitative analysis of AE data, and its correlation with material weakening, the mechanical behaviour of rock under uniaxial compression was inferred.

Eberhardt et al. (1998) utilised a moving point regression technique to assess the volumetric and axial stiffness of stressed rock specimens in order to identify the brittle failure stages outlined by Brace (1964) and Bieniawski (1967). This process requires a moving average interval or 'window' be selected. Based on sensitivity analysis, Eberhardt et al. (1998) recommends an interval size five per cent of the total data set. It was also noted that increasing the size of this interval smooths the general relation, while decreasing it produces more frequent peaks and troughs in the data. Volumetric strain $\left(\varepsilon_{v}\right)$ and stiffness $\left(\bar{E}_{v o l}\right)$ relations for cylinders are given by Equations (1) and (2):

$$
\varepsilon_{v}=\varepsilon_{a}+2 \varepsilon_{h}
$$

where:

$$
\begin{aligned}
& \varepsilon_{a}=\text { Axial strain. } \\
& \varepsilon_{h}=\text { Hoop strain. }
\end{aligned}
$$

$$
\bar{E}_{v o l}=\frac{\Delta \sigma_{a}}{\Delta \varepsilon_{v}}
$$

Work on specimens that contained a healed joint has been carried out by Lei et al. (2003). Their findings are based on a sample of granite porphyry containing a single, pre-existing, naturally healed joint. From this work they concluded that the failure of the healed joint demonstrated a hierarchical failure that could be described by three stages; dynamic failure of the fault, asperity failure and finally, microcracking at a micrometer to millimetre scale.

Prikryk et al. (2003) looked at rock fabric effects on AE including the relationship of grain size to AE energy. It was found that an increase in mean grain size of three times will cause an increase in relative $\mathrm{AE}$ energy of 100 times due to the 10 fold increase in crack area that a grain size increase brings about. Kusunose et al. (1991) also noted a grain size to AE relationship in his work.

While the AE energy produced from a rock sample is a relative measure it remains hard to apply the grain size-energy findings generally to various different test specimens. Once this energy measure can be consistently quantified and repeatability is no longer an issue, it seems probable that, with knowledge of a rock's grain size, it would be possible to predict the characteristic value of the AE distribution and subsequently relate this characteristic energy level to a point along the stress-strain curve and estimate the point at which total failure will occur.

Rudajev et al. (1994) established that the energy-frequency distribution of rock samples under uniaxial loading followed a bilogarithmic curve throughout the test. This is confirmed by Prikryk et al. (2003). They also show that the mean relative energy of the AE events remains approximately constant throughout the time domain, only showing an increase in the final time period. Prikryk et al. (2003) accounts for this solo increase with the failure of large grains which give off comparatively higher energies and only fail at near peak and peak stresses.

This paper aims to further asses the applicability of AE monitoring techniques to brittle rock failure. It will compare and explore the stress levels at which the different failure stages occur using both traditional stressstrain derived relations and AE readings. The application of these findings to useful engineering design will 
be looked at in the hope that a consistent and repeatable process can be established to derive common material parameters.

\section{Methodology}

\subsection{Properties of tested quartzite}

Uniaxial compression testing of quartzite was carried out in the laboratory. The specimens were cylindrical core specimens of $83 \mathrm{~mm}$ in diameter and roughly twice that in length. The quartzite was sourced between reduced levels of 68-78 $\mathrm{m}$ and formed a geological unit between 85-130 m thick. The rock mass was found to be massive in nature, with interbedded shales. The specimens chosen were selected so as to avoid the shale interbeds; features not examined in this study. Where jointing occurred it was consistent, sub vertical and terminated at the shale beds. The intact rock properties of the quartzite specimen examined in this paper are shown in Table 1 . Chemically the rock was known to contain $\mathrm{Al}, \mathrm{K}, \mathrm{Ca}, \mathrm{Mg}$, $\mathrm{Ti}$ and $\mathrm{Zr}$ although this mineralisation occurred mainly in the shale interbeds.

\section{Table 1 Measured core specimen properties}

\begin{tabular}{ll}
\hline Diameter & $83.3 \mathrm{~mm}$ \\
Height & $184.3 \mathrm{~mm}$ \\
Density & $2600 \mathrm{~kg} / \mathrm{m}^{3}$ \\
UCS & $151.5 \mathrm{MPa}$ \\
Young's modulus (average modulus of linear portion) & $76 \mathrm{GPa}$ \\
Poisson's ratio & 0.11 \\
\hline
\end{tabular}

\subsection{Specimen preparation}

The samples were prepared in accordance with ASTM D4543-01 (ASTM, 2001). The high quality diamond core meant that side straightness of the specimen was well within the stipulated tolerances. End flatness was achieved by machining the specimen ends in a specially constructed v-block clamp fixed to a high quality tool and cutter grinder. A diamond cup wheel with a 126 grit size suitable for roughing and finishing precision tools was used to grind the end surfaces. Once the specimen was clamped in the v-block it was not removed until both ends were ground. Here the entire v-block clamping system was rotated and relocated on the feeder table. These techniques and procedures ensured that the ends were parallel.

\subsection{Uniaxial testing}

The tests were conducted in accordance with ASTM D7012-04 (ASTM, 2004). A strain controlled Amsler loading frame with a $5000 \mathrm{kN}$ capacity was used in the testing. Two Schaevitz LVDTs were used to measure the axial displacement to a reported accuracy of $0.375 \%$ of the full range. These respective displacements were averaged when used to calculate the applied strain.

Four $68 \mathrm{~mm}$ long Kyowa strain gauges were attached to the specimen; two axially and two laterally around the specimen mid-height at $90^{\circ}$ intervals, such that the axial strain gauges were separated by $180^{\circ}$. To avoid faulty strain readings resulting from artificial strength variations due to the gauge adhesive, or defects and voids in the rock surface where strain measurements may have been more representative of the adhesive rather than the rock under examination, a two stage application process was used. After accurate centres and alignment lines were marked on the specimen a layer of epoxy resin was applied to the rock surface over these markings. This resin filled any surface irregularities and pore spaces. After the epoxy had cured it was sanded back to the original surface level of the rock, leaving in situ any resin that had filled irregularities and pore voids of the rock along the gauging area. These areas were then cleaned and neutralised prior to the application of the strain gauges using the recommended adhesive. The data acquisition system recorded the strain, displacement and force readings at a rate of $10 \mathrm{~Hz}$. 


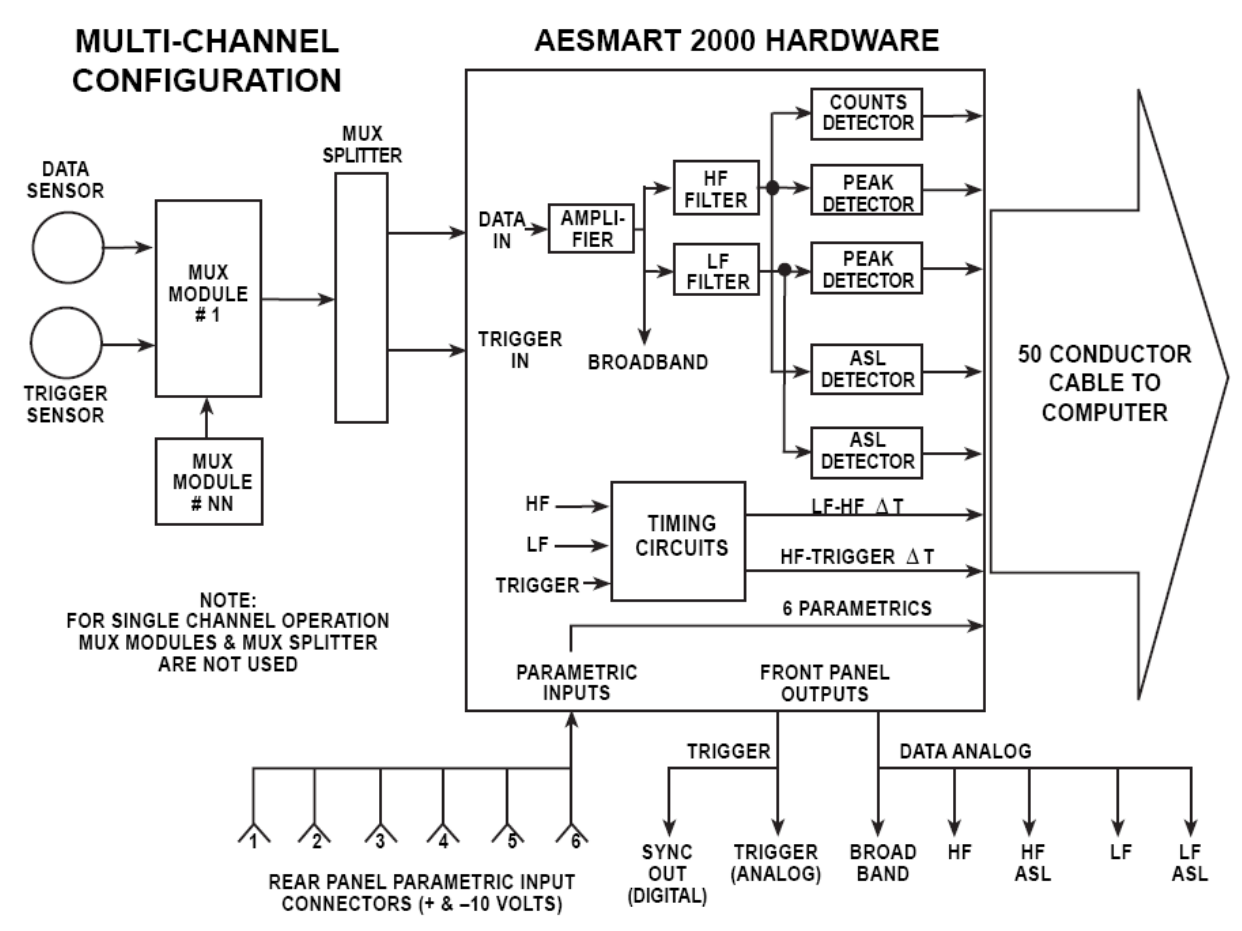

Figure 1 Simplified AE data flow diagram (DECI, 2000)

The AE data was monitored and recorded using an AESMART 2000 DECI24 AE system. The data flow diagram is shown in Figure 1. Data acquisition took place at a rate of one Hz. System gain; trigger, low and high frequency thresholds were set at 50,60 and $60 \mathrm{~dB}$ respectively. The low and high frequency gain was increased from the manufacturer's default setting of $50 \mathrm{~dB}$ to increase the system's sensitivity. Ring-down count thresholds were set at $100 \mathrm{mV}$ for low frequency and $200 \mathrm{mV}$ for high frequency, trigger input and event count parameters. The AE sensor was fixed to the bottom loading platen $20 \mathrm{~mm}$ away from the rock sample (Figure 2). Petroleum jelly was applied to the sensor prior to it being fixed in place with tape. Had the sensor been attached directly to the specimen, instead of the platen, clearer AE measurements would have been obtained. Although, due to the explosive nature of the specimen's failure, this option was not pursued in order to protect the transducer from damage.

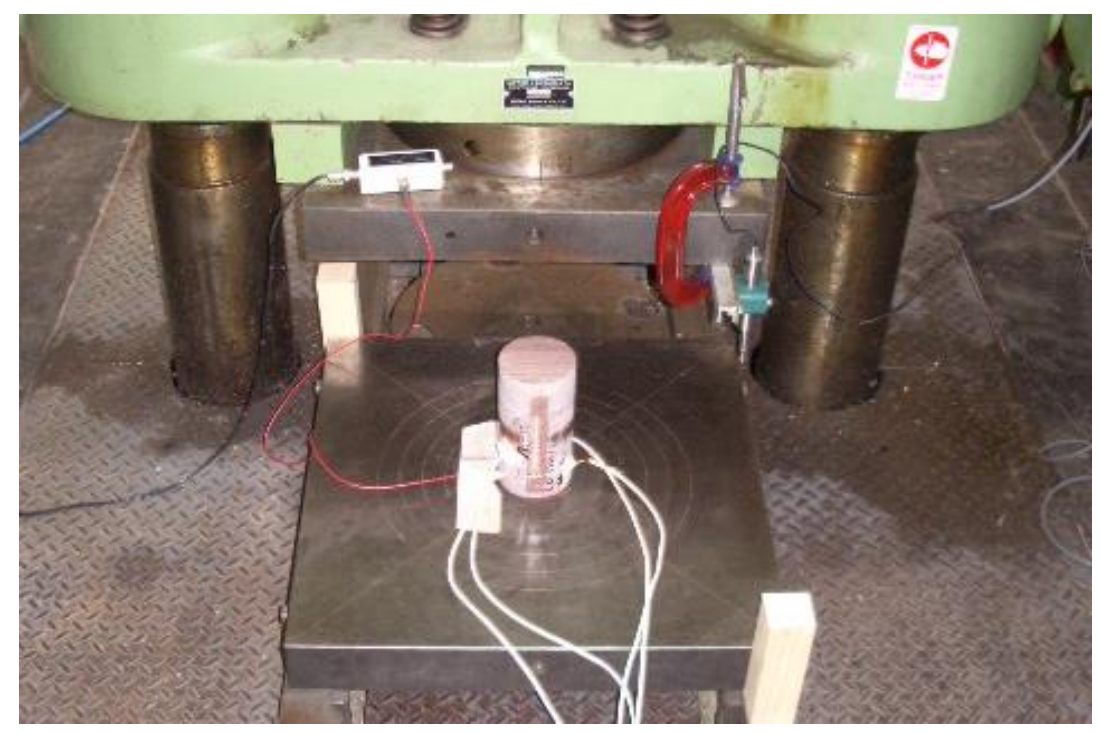

Figure 2 Laboratory setup showing sample and location of AE sensor on lower platen left of sample 


\section{Results}

The laboratory techniques used in this study aim at assessing the behaviour and strength properties of quartzite through both traditional (stress-strain) and (AE) monitoring techniques. These two different techniques were used to assess the damage mechanics, Young's modulus and Poisson's ratio of the specimen in order to make critical comparisons of their respective results.

Figure 3 shows the axial stress versus lateral and axial strain relationships. These data were obtained from averaging the strain readings of two opposing lateral and axial strain gauges. Both lateral and axial strains show a strong linear relationship with axial stress from the onset of loading until just prior to peak stress. The post peak relation was unable to be captured due to insufficient stiffness of the loading frame compared to that of the sample. It was from these data that average volumetric stiffness (Figure 4) was derived using Equations (1) and (2).

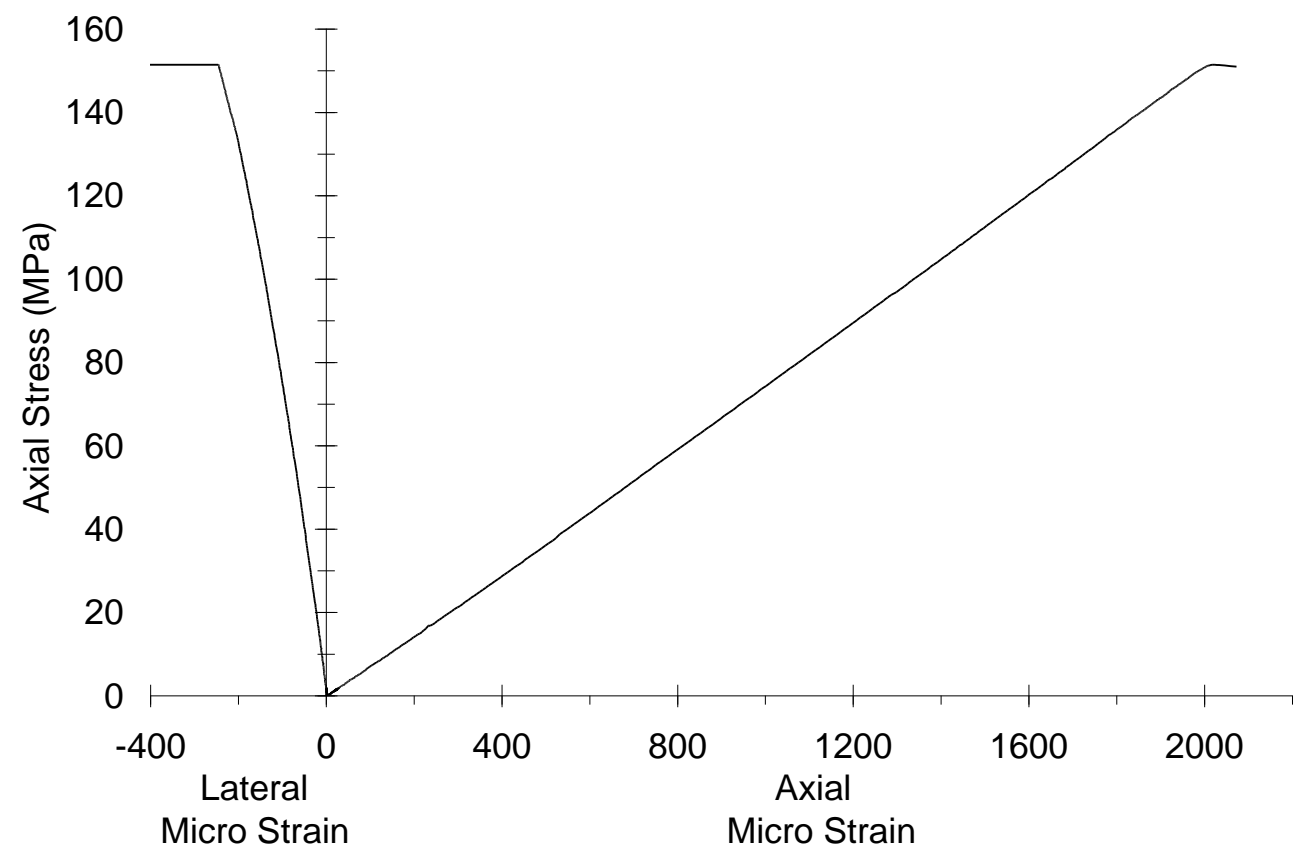

\section{Figure 3 Axial stress versus axial strain and lateral strain}

Figure 4 shows average volumetric stiffness versus axial stress. Traditionally this measure has been used to monitor the various stages of brittle rock and concrete failure. Recently Eberhardt et al. $(1999 ; 1998)$ and Ranjith et al. (2008) have explored this approach in uniaxial testing of rock, Lac du Bonnet granite, and concrete failure respectively. As described in the introduction several stages have been identified in the brittle failure process (Bieniawski, 1967; Brace, 1964). These stages have been indicated in Figure 4 and Figure 5 and mark:

- The end of crack closure and onset of linear elastic deformation $\left(\sigma_{c c}\right)$.

- The onset of crack initiation and stable crack growth $\left(\sigma_{c i}\right)$.

- The onset of crack coalescence and unstable crack growth $\left(\sigma_{c s}\right)$.

- Crack damage onset $\left(\sigma_{c d}\right)$.

In assigning the onset of these failure stages the method suggested by Eberhardt et al. (1999) was utilised with minor adaptation. In the work of both Eberhardt et al. (1998) and Chang and Lee (2004), a five per cent regression window was recommended when constructing the average volumetric stiffness curve. The data presented in Figure 4 utilises only a three per cent regression window. It was found that increasing the window to the five per cent level suggested by Eberhardt et al. (1998) and Chang and Lee (2004), concealed 
key rate changes that were necessary in assigning the failure onset thresholds. This lower regression window was required when other similar data were analysed in the same way. Decreasing the regression window further led to the appearance of further peaks and troughs that could have been identified as these same rock failure thresholds. The fact that a minor change in this seemingly arbitrary variable can lead to vastly different conclusions being drawn from the same data, indicates the subjective nature of the average volumetric stiffness versus axial stress approach to establishing the failure onset thresholds. It may also be possible that the necessary change in the regression window here was brought about by the higher sampling rate utilised in this work, approximately double that used by Eberhardt et al. (1998) and five times greater than that used by Chang and Lee (2004). But this effect was not explored further in this study.

Table 2 summarises the different threshold levels obtained using the average volumetric stiffness curve and AE monitoring results. Considering the volumetric stiffness plot; the region spanning from $0-25$ (70 MPa depending on interpretation and the moving average window selected) is considered to include crack closure. This point was selected as the occasion where axial and volumetric stiffness tended towards constant (or linearity in the slope of the axial and volumetric stiffness curves). From 25 (70 MPa) to 96 (117 MPa) linear elastic behaviour is dominant. The end of this range was identified as the point at which the average volumetric stiffness curve departed from linearity. Following this stage of linear behaviour, crack initiation and stable crack growth occurs until a $137 \mathrm{MPa}$ stress level. Interestingly, this marks a point roughly equal to $90 \%$ of the uniaxial compressive strength (UCS). The region from 137-150 MPa demonstrates crack coalescence or shear cracking. The onset of this region is considered the point at which the average volumetric stiffness curve begins to show large instantaneous variations in magnitude. Crack damage is initiated at $150 \mathrm{MPa}$ and the peak stress experience by the rock specimen was $151.5 \mathrm{MPa}$. The onset of crack damage is taken as the point where average volumetric stiffness moves from positive to negative.

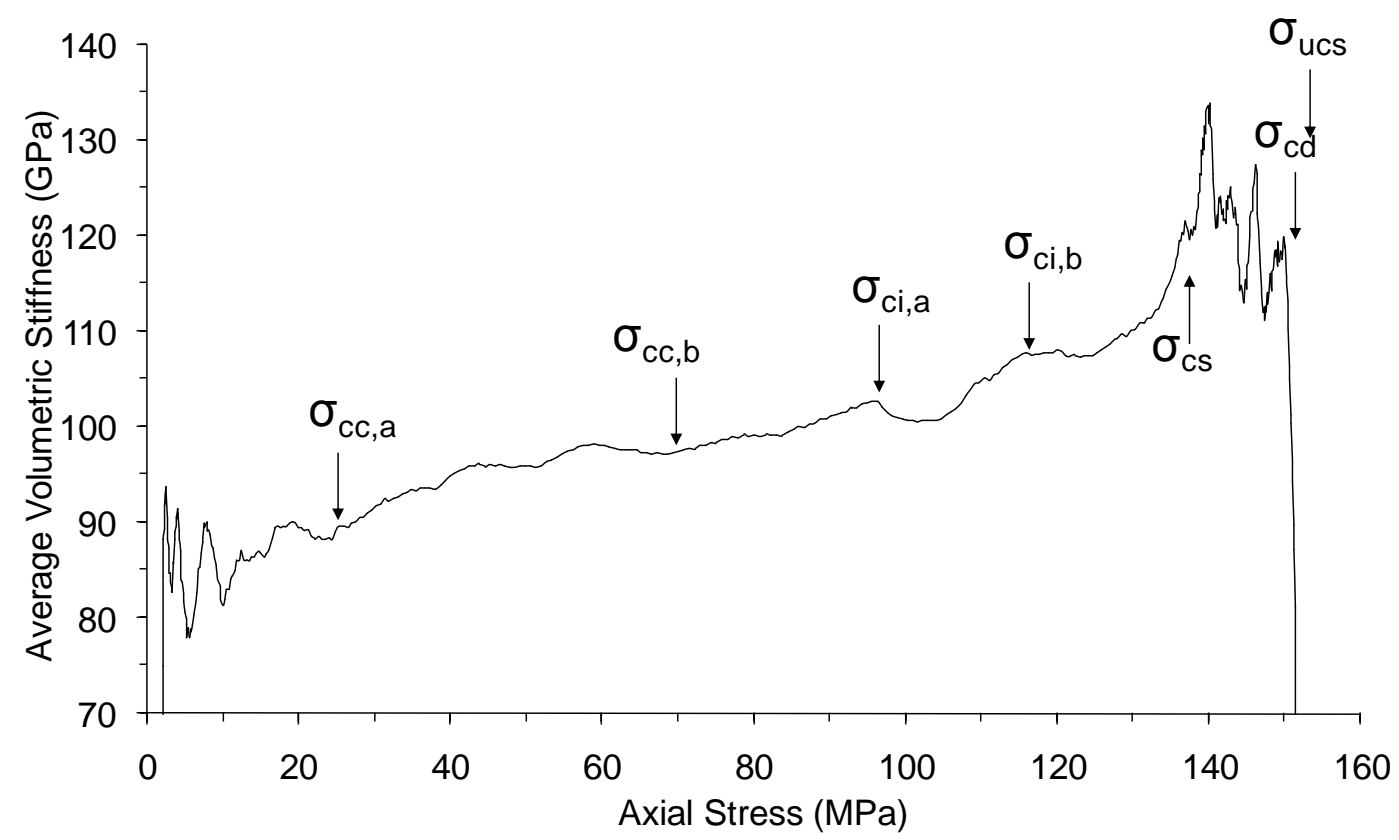

Figure 4 Average volumetric stiffness (using a moving average window incorporating three per cent of the total number of data pairs)

Assessing the same thresholds using recorded AE data, we see initial spikes at 34 and $58 \mathrm{MPa}$ (Figure 5(a)). Either of these values could be taken as the end of crack closure and the beginning of the linear elastic behaviour. This is the only ambiguous stress threshold boundary. The remaining onset thresholds are clearly defined, with outstanding peaks marking their locations (Figure 5(b)). 


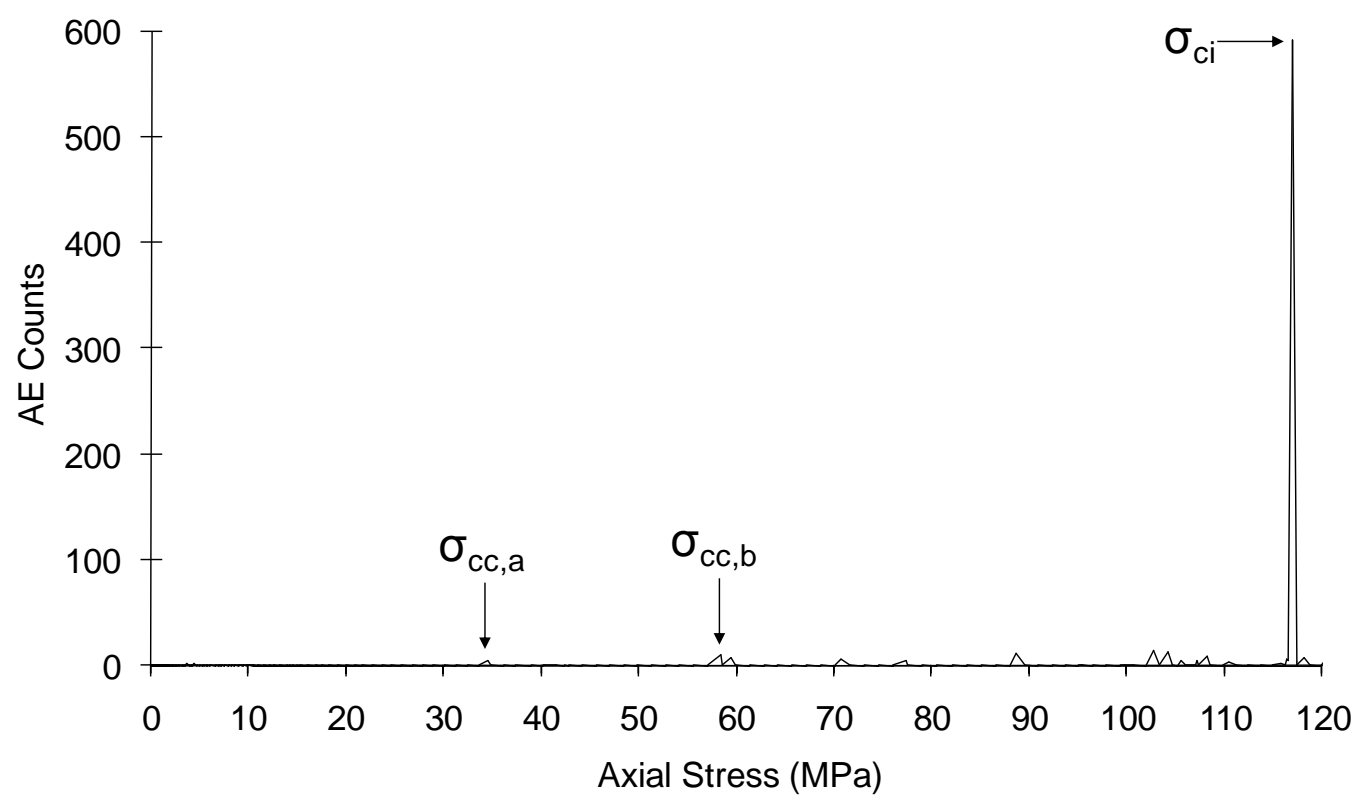

Figure 5 (a) AE counts versus axial stress (Note: initial stress range shown $(0 \leq \sigma \leq 120))$

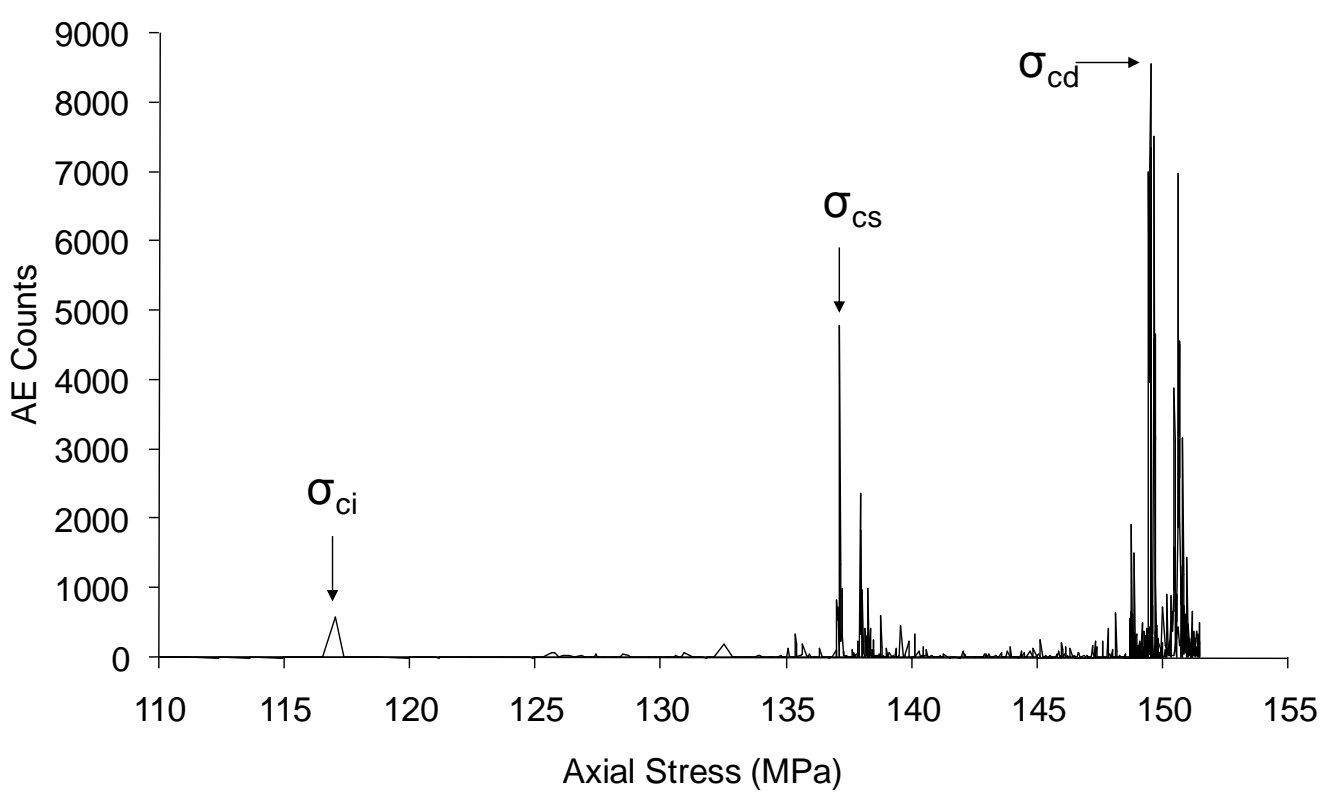

Figure 5 (b) AE counts versus axial stress (Note: final stress range shown $(110 \leq \sigma \leq 155))$

Comparing the failure stage boundaries (Table 2) there is clearly discrepancy between the two methods utilised. Both produce ambiguous linear elastic onset boundaries $\left(\sigma_{c c}\right)$. The crack initiation boundary is clearly defined in the $\mathrm{AE}$ plot with a peak at $117 \mathrm{MPa}$. Comparatively, depending on the moving average window selected to construct the average volumetric stiffness plot, this same boundary is more ambiguous on the average volumetric stiffness plot. The crack coalescence boundary was found to be identical using both methodologies. This boundary (137 MPa) is equal to $90 \%$ of the UCS of the specimen. A similar relationship was seen in other specimens tested. It is foreseeable that this knowledge could be used as an input variable into a constitutive model defining completely the limits of elastic behaviour and the onset of 
non-linearity. From uniaxial testing the crack initiation and coalescence onset points can be established as a $\%$ of UCS. For the quartzite tested here this percentage falls at $90 \%$ of the UCS $\pm 4 \%$ for the onset of crack coalescence. These known threshold values could then be used to control at what point the model reverts to some form of inelastic crack damage model, for example.

Table 2 Comparison of failure stage initiation as found using average volumetric stiffness and AE techniques

\begin{tabular}{lcc}
\hline \multirow{2}{*}{ Failure Stage } & \multicolumn{2}{c}{ Failure Stage Initiation Stress (MPa) } \\
\cline { 2 - 3 } & Volumetric Stiffness & AE \\
\hline Crack closure upper limit and linear elastic deformation onset, $\sigma_{c c}$ & 25 or 70 & 34 or 58 \\
Crack initiation and stable growth, $\sigma_{c i}$ & 96 or 117 & 117 \\
Crack coalescence and unstable crack growth, $\sigma_{c s}$ & 137 & 137 \\
Crack damage, $\sigma_{c d}$ & 150 & 149.5 \\
UCS, $\sigma_{u c s}$ & 151.5 & 151.5 \\
\hline
\end{tabular}

Selection of an appropriate method to establish Young's modulus and Poisson's ratio is often subjective and the results obtained can vary considerably depending on the methods selected. Figure 6 shows this comparison following the recommended methods outlined in the ASTM D7012-04 standard (ASTM, 2004), the method suggested by Eberhardt et al. (1998), and a proposed adaptation of the ASTM secant modulus method. The method suggested by Eberhardt et al. (1998) uses the average modulus of the stress-strain curve between the stress limits $\sigma_{c c}$ to $\sigma_{c i}$ (the linear elastic region) and produces a Young's modulus and Poisson's ratio almost identical to that obtained using the secant modulus method (taking the secant to a stress equal to $50 \%$ of the UCS). Likewise, using the linear elastic boundaries defined by the AE results instead of the average volumetric stiffness boundaries, good comparisons can be made with the modified ASTM method. In this modified method the secant is taken to the crack coalescence onset stress (a value shown in this paper to be well defined in brittle rock). Although the variation between all these methods is not extremely wide, it seems that a possible outcome from further research could be the development of a consistent method for which Young's Modulus and Poisson's ratio can be obtained for engineering design.

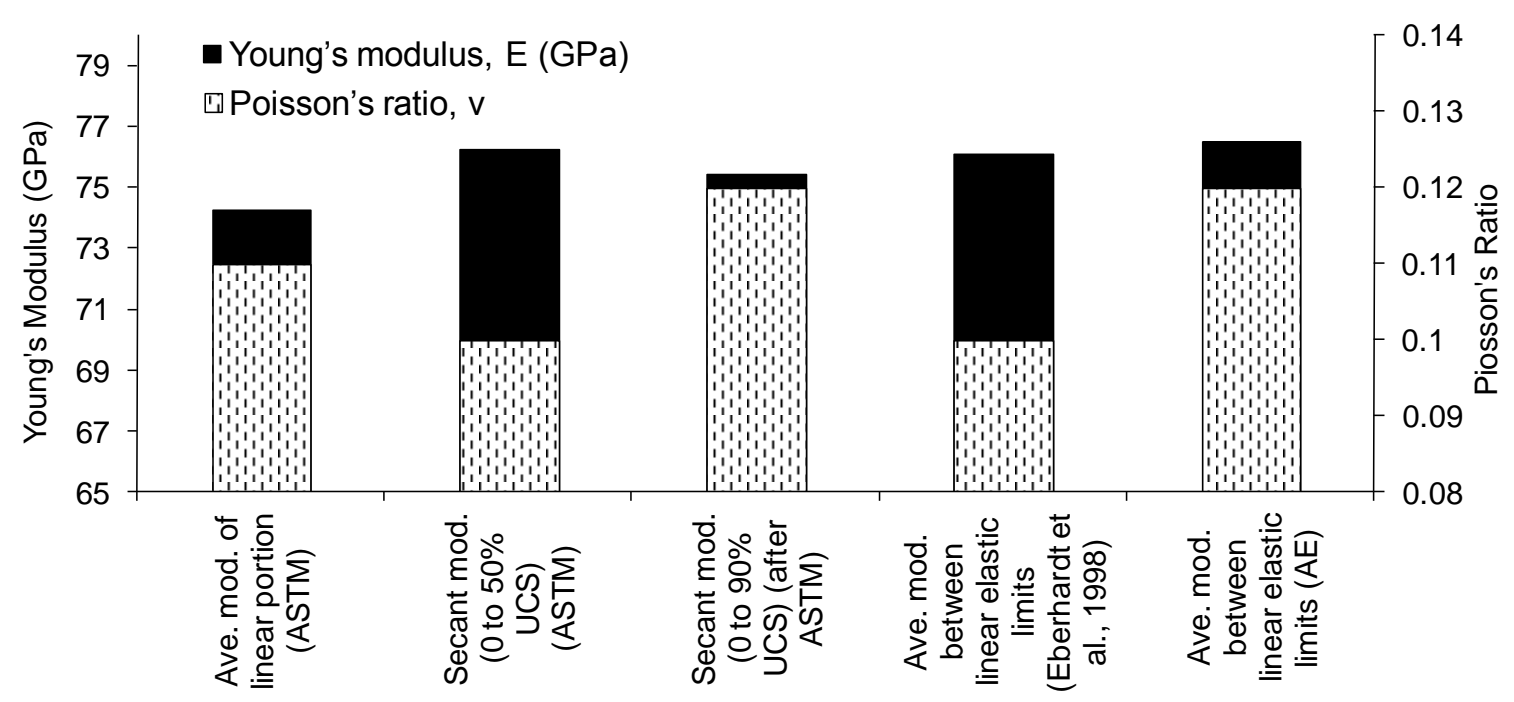

Figure 6 Comparison of Young's modulus and Poisson's ratio using various methodologies 


\section{Conclusions}

Through the completion of uniaxial testing on $83 \mathrm{~mm}$ quartzite cores the brittle rock failure process has been examined. This was done utilising stress-strain along with AE readings. The results obtained using each method was comparable to some extent. Although it should be noted that the brittle failure limits obtained from the stress-strain data took a considerable amount of effort and data manipulation to extract. In the process of their extraction, a considerable subjective judgement had to be employed. Comparatively though, the brittle failure limits obtained from the AE data were obtained extremely easily. No data manipulation was required to the point where it was possible to identify the different failure onsets in real time while testing was carried out.

Both the methods used identified the point at which crack coalescence began (unstable peaks and troughs on the average volumetric stiffness curve, and a significant and recognisable peak in the AE data). This point marked a stress equal to $90 \%$ of the specimen's UCS. This point was observed in other similar testing completed on brittle rock. Implementation of this information could be used in a constitutive model that toggles from an elastic failure model to a crack damage failure model at a point predefined by this measurable stress level. With knowledge of the points in the stress path that coincide with changes in material behaviour a more complete model of the materials behaviour would be constructed. Knowledge of these brittle failure boundaries can also be used to estimate Young's modulus and Poisson's ratio. Eberhardt et al. (1998) suggested using the linear elastic portion of the stress-strain curve as defined by the failure boundaries $\sigma_{c c}$ to $\sigma_{c i}$ to estimate the above modulus and ratio. This result was compared to standard methods of establishing these figures as defined in the ASTM standard and also to a secant modulus method where the onset of crack coalescence (or 90\% UCS) was used as the secant point. This value was chosen as it marks the end of the linear axial stiffness behaviour and is also readily recognisable from AE results.

\section{References}

ASTM (2001) Standard practices for preparing rock core specimens and determining dimensional and shape tolerances, Annual Book of ASTM Standards, Designation: D4543-01, ASTM International, West Conshohocken, Pennsylvania, $5 \mathrm{p}$.

ASTM (2004) Standard test method for compressive strength and elastic moduli of intact rock core specimens under varying states of stress and temperatures, Annual Book of ASTM Standards, Designation: D7012-04, ASTM International, West Conshohocken, Pennsylvania, 8 p.

Bieniawski, Z.T. (1967) Mechanics of brittle rock fracture: Part 1 - Theory of the fracture process, Int. J. Rock Mech. Min. Sci. and Geomech. Abstr., 4(4), pp. 395-406.

Brace, W.F. (1964) Brittle fracture of rocks, State of Stress in the Earths Crust: Proceedings of the International Conference, Judd, W.R. (editor), American Elsevier, Santa Monica, pp. 110-178.

Chang, S-H. and Lee, C-I. (2004) Estimation of cracking and damage mechanisms in rock under triaxial compression by moment tensor analysis of acoustic emission, Int. J. Rock Mech. Min. Sci., 41, pp. 1069-1086.

Cox, S.J.D. and Meredith, P.G. (1993) Microcrack formation and material softening in rock measured by monitoring acoustic emissions. Int. J. Rock Mech. Min. Sci. and Geomech. Abstr. 30(1), pp. 11-24.

DECI (2000) Manual For Setup and Operation of AESMART 2000 Acoustic Emission System, Duegan Engineering Company Inc., San Juan Capistrano, California, 7 p.

Eberhardt, E., Stead, D. and Stimpson, B. (1999) Effects of sample disturbance on the stress induced microfracturing characteristics of brittle rock, Can. Geotech. J., 36, pp. 239-250.

Eberhardt, E., Stead, D., Stimpson, B. and Read, R.S. (1997) Changes in acoustic event properties with progressive fracture damage, Int. J. Rock Mech. Min. Sci., 34(3-4), 071B.

Eberhardt, E., Stead, D., Stimpson, B. and Read, R.S. (1998) Identifying crack initiation and propagation thresholds in brittle rock, Can. Geotech. J., 35, pp. 222-233.

Filimonov, Y., Lavrov, A. and Shkuratnik, V. (2005) Effect of confining pressure on acoustic emission in ductile rock, Strain, 41, pp. 33-35.

Kusunose, K., Lei, X., Nishizawa, O. and Satoh, T. (1991) Effect of grain size on fractal structure of acoustic emission hypocenter distribution in granitic rock, Phys. Earth Plant. Interior, 67, pp. 194-199.

Lei, X., Kusunose, K., Satoh, T. and Nishizawa, O. (2003) The hierarchical rupture process of a fault: an experimental study. Physics of the Earth and Planetary Interiors, 137, pp. 213-228.

Lockner, D.A., Byerlee, J.D., Kuksenko, V., Ponomarev, A. and Sidorin, A. (1991) Quasi-static fault growth and shear fracture energy in granite, Nature, 350, pp. 39-42.

Lockner, D.A. (1993) The role of acoustic emission in the study of rock fracture, Int. J. Rock Mech. Min. Sci. Geomech., 30, pp. 883-899. 
Prikryl, R., Lokajicek, C., Li, C. and Rudajev, V. (2003) Acoustic emission characteristics and failure of uniaxially stressed granitic rocks: the effects of rock fabric, Rock Mech. Rock Engng., 36(4), pp. 225-270.

Ranjith, P.G., Jasinge, D., Song, J.Y. and Choi, S.K. (2008) A Study of the effect of displacement rate and moisture content on the mechanical properties of concrete: Use of acoustic emission, Mechanics of Materials, 40, pp. $453-469$.

Rudajev, V., Vilhelm, J., Kozak, J. and Lokajicek, T. (1994) Complex analysis of acoustic emission from loaded rock samples, Progress in Acoustic Emission VII, Proceedings of The 12th International Acoustic Emission Symposium, T. Kishi, Y. Mori and M. Enoki (editors), The Japanese Society for NDI, Sapporo, Japan, pp. 243-248.

Yoshikawa, S. and Mogi, K. (1981) A new method for estimation of the crustal stress from cored rock samples: Laboratory study in the case of uniaxial compression, Tectonophysics, 74, pp. 323-339. 